\title{
Effects of cryopreservation on sperm quality, nuclear DNA integrity, in vitro fertilization, and in vitro embryo development in the mouse
}

\author{
Cengiz Yildiz ${ }^{1,2}$, Palma Ottaviani ${ }^{1,2}$, Napoleon Law ${ }^{1,2}$, Renise Ayearst ${ }^{1,2}$, Ling Liu ${ }^{1,2}$ and \\ Colin McKerlie ${ }^{1,2}$ \\ ${ }^{1}$ Integrative Biology Research Program, The Hospital For Sick Children, Toronto, Ontario, Canada M5G 1 X8 \\ ${ }^{2}$ Department of Laboratory Medicine and Pathobiology, University of Toronto, Toronto, Ontario, Canada M5G 1X8
}

Correspondence should be addressed to C McKerlie, Integrative Biology Research Program, The Hospital For Sick Children, Toronto, Ontario, Canada M5G 1X8; Email: colin.mckerlie@sickkids.ca

\begin{abstract}
Efficient freezing, archiving, and thawing of sperm are essential techniques to support large scale research programs using mouse models of human disease. The purpose of this study was to investigate the effects of variable combinations and concentrations of cryoprotectants on sperm-assessment parameters of frozen-thawed mouse sperm in order to optimize cryopreservation protocols. Sperm was frozen using combinations of $3 \%$ skim milk +0.2 or $0.3 \mathrm{M}$ nonpermeating raffinose with either permeating glucose, fructose, propylene glycol, ethylene glycol, glycerol, or sodium pyruvate in CD-1, C3FeB6F1/J, B6129SF1,

C57BL/6NCrIBR, 129S/SvPaslco, and DBA/2NCrIBR mice. Sperm-assessment parameters included progressive motility, plasma membrane integrity (SYBR-14 + PI), in vitro fertilization rate, and in vitro embryo development rate to blastocyst. DNA content analysis of sperm was measured by the sperm chromatin structure assay (SCSA). $0.3 \mathrm{M}$ raffinose with $0.1 \mathrm{M}$ fructose significantly improved post-thaw sperm-assessment parameters for CD-1, C3B6F1, B6129SF1 mice $(P<0.05-0.01)$, whereas 0.2 M raffinose with $0.1 \mathrm{M}$ glycerol or $0.1 \mathrm{M}$ fructose enhanced sperm assessment values for $\mathrm{C} 5 \mathrm{BL} / 6$ and $129 \mathrm{~S}$ mice $(P<0.01)$, compared to 0.3 $\mathrm{M}$ raffinose alone. DNA fragmentation during cryopreservation was significantly increased in all strains evaluated when compared with fresh control sperm in a strain-dependent manner $(\boldsymbol{P}<0.01)$. Supplementation with permeating glycerol or fructose to the cryoprotectant (CPA) solution showed a significant protective effect to DNA integrity when cryopreserving sperm from C57BL/6 and 129S mice. Damage to sperm DNA significantly decreased the rate of in vitro embryo development to blastocyst in C57BL/6 mice. The type of monosaccharide sugar or polyols, CPA molarity, and combination of permeating and nonpermeating cryoprotectant are significant factors for improving progressive motility, plasma membrane integrity, DNA integrity, in vitro fertilization rate, and in vitro embryo development rate to blastocyst in cryopreserved mouse sperm.

Reproduction (2007) 133 585-595
\end{abstract}

\section{Introduction}

The mouse has become a significant research tool in genetic and molecular biology allowing the study of many models of human diseases based on transgenic or targeted mutations (Thornton et al. 1999, Crister \& Mobraten 2000). The mouse is a convenient model because of its well-characterized genome and ease of genetic and experimental manipulation. Due to increasing demand for archiving through cryopreservation of newly emerging lines of outbred, hybrid, and inbred mutant mice, many laboratories have been working to better understand the freezing and thawing properties of mouse sperm in order to find more efficient methods for sperm storage and recovery. The primary problem in mouse sperm cryopreservation is that it becomes very sensitive to cold and osmotic effect (Critser \& Mobraten 2000). The most commonly described adverse effect of freeze-thawing on mouse sperm is the dramatic and sharp decrease in sperm motility and plasma membrane integrity (Songsasen \& Leibo 1997a, Sztein et al. 2000, 2001, Nishizono et al. 2004). Therefore, factors such as the type of cryoprotectant agents (CPA) used and genetic background of the mice all contribute to the successful cryopreservation of mouse sperm.

The CPA used in mouse sperm cryopreservation, whether permeating, nonpermeating, or combined is a key element. Polge et al. (1949) first reported that 
glycerol had a protective action on the survival of frozen-thawed spermatozoa of chicks and humans. The CPA provides a protective action as an energy source for spermatozoa (Watson 1979) and maintains the osmotic pressure by forming hydrogen bonds with membrane phospholipids and sugars reducing membrane damage and minimizing membrane destabilization during freezing and thawing (Strauss et al. 1986). The first successful CPA used with mouse sperm consisted of a combination of $3 \%$ skim milk and $18 \%$ raffinose (Tada et al. 1990, Takeshima et al. 1991). This CPA combination was further improved by Nakagata (1995) and Nakagata et al. (1992). The CPA produced normal offspring that were derived from cryopreserved oocytes fertilized in vitro by cryopreserved sperm (Nakagata 1993). Another successful CPA for mouse sperm consists of a mixture of raffinose, glycerol, and egg yolk (Songsasen \& Leibo $1997 a, 1997 b)$. Other studies have used mono-, di- and tri- saccharides, polyols (e.g. glycerol, or DMSO), and macromolecules (e.g. polyvinylpyrrolidone, or metrizamide) alone or in combination with conventional CPAs (Storey et al. 1998, An et al. 2000, Sztein et al. 2001, Thampson et al. 2001'Koshimoto \& Mazur 2002) to improve the efficiency of mouse sperm cryopreservation.

It is well established that the genetic background of outbred, hybrid, and inbred strains of mice also influence sperm-assessment parameters (Songsasen \& Leibo 1997a, Sztein et al. 2000, Nishizono et al. 2004), in vitro fertilization rate (Kasai et al. 1978, Hoppe 1980, Niwa et al. 1980, Sztein et al. 2000), and in vitro embryo development rate (Dandekar \& Glass 1978, Roudebush \& Duralia 1996, Scott \& Whittingham 1996, Sztein et al. 2000). Unfortunately, inbred strains, such as C57BL/6 and $129 \mathrm{~S}$ that are among the most commonly used strains of mice for the production of mutant lines still pose a challenge to obtaining consistently high freezethaw sperm quality, in vitro fertilization rate, and livebirth rate compared to most outbred and hybrid strains (Songsasen \& Leibo 1997a, Sztein et al. 2000, Nishizono et al. 2004).

The integrity of mammalian sperm DNA is of prime importance for the paternal genetic contribution to normal offspring. Damaged DNA can have a significant negative impact on oocyte fertilization, embryo development rate, and live-birth rate. A significant correlation between the presence of nuclear DNA alterations in mature spermatozoa and poor sperm parameters or impaired reproductive efficiency is reported in both humans and animals (Ron-el et al. 1991, Hughes et al. 1996, Edwards \& Beard 1999). To date, studies show that the cryopreservation process causes DNA damage to mammalian sperm in human (Royere et al. 1988, 1991, Donnelly et al. 2001, Hammadeh et al. 2001), boar (Fraser \& Strzezek 2004), and ram (Peris et al. 2004).

The purpose of this study was to examine seven different CPAs in a prototypic hybrid strain of mice to determine the optimal CPA for sperm cryopreservation.
Using this optimal CPA, different molar concentrations and combinations were then used to assess its effects on progressive motility, plasma membrane integrity, DNA integrity, in vitro fertilization rate, and in vitro embryo development rate to blastocyst in a number of outbred, hybrid and inbred strains of mice.

\section{Materials and Methods}

\section{Animals}

Outbred male (CD-1), hybrid female (B6C3F1/CrlBR), and inbred male mice (DBA/2NCrIBR, 129S/SvPaslco, C57BL/6NCrlBR) were obtained from Charles River Canada (St-Constant QC, Canada). Hybrid B6129SF1 mice were obtained from Taconic (Germantown, NY, USA). Hybrid C3FeB6F1/J mice were purchased from The Jackson Laboratories (Bar Harbor, ME, USA). All sperm-donor mice ranged from 12 to 15 weeks of age and were sacrificed by cervical dislocation. Females ranged from 4 to 5 weeks of age and were sacrificed in the same manner. During all experiments, mice were housed under controlled light conditions $(12 \mathrm{~h}$ light:12 h darkness) at the Laboratory Animal Services facilities of The Hospital for Sick Children, maintained in pathogen free holding, and received standard mouse diet and water ad libitum. Their use and care at the Hospital were reviewed in advance and performed according to standards of the Canadian Council on Animal Care (CACC).

\section{Reagents}

Unless otherwise stated, all reagents were purchased from Sigma Chemical Company.

\section{Summary of experimental design}

Experiment 1 evaluated the effects of seven different cryoprotectants, sugars, and polyols, on sperm-assessment parameters. Fresh sperm samples were obtained from B6129SF1 mice and frozen using a programmable controlled-rate freezer. The results obtained from experiment 1 were analyzed and the two cryoprotectants that provided the best results were used for further evaluation in experiment 2 .

Experiment 2 assessed the optimal CPA concentrations of 0.2 and $0.3 \mathrm{M}$ raffinose alone and combined with permeating CPA in CD-1, C3B6F1, B6129SF1, C57BL/6, $129 S$, and DBA mice. Sperm obtained from donors was frozen using a manual freezing technique and tested for post-thaw progressive motility, plasma membrane integrity, and DNA integrity.

Experiment 3 studied the effects of the optimal CPA combinations identified in experiment 2 in $\mathrm{C} 3 \mathrm{~B} 6 \mathrm{~F} 1$ and C57BL/6 mice on unassisted in vitro fertility rate and in vitro embryo development rate to blastocyst. 


\section{Cryoprotectant agents}

The seven CPA used in these studies were prepared according to the method described by Nakagata (2000). A measure of $0.2 \mathrm{M}$ raffinose ( $\mathrm{D}+$ raffinose pentahydrate) sugar was combined with either glucose, fructose, propylene glycol, ethylene glycol, glycerol, or sodium pyruvate ( $0.1 \mathrm{M}$ and different amounts). Osmotic pressures were adjusted to $430-450$ and $470-490 \mathrm{mOsm} / \mathrm{l}$ as shown in Table 1; 330-350 and 600-620 mOsm/l as in Tables 2 and 3 (Advanced Instruments, Inc., Model 3300, Norwood, Massachusetts, USA).

The buffer used was Bacto Difco powder (Becton Dickinson, Franklin Lakes, NJ, USA) (w/v) dissolved in distilled water at $45{ }^{\circ} \mathrm{C}$. The solution was centrifuged at 14000 r.p.m. for $15 \mathrm{~min}$ at room temperature and the resulting supernatant was filtered through $0.45 \mu \mathrm{m}$ Millipore filters (Carrigtwohill, Co. Cork, Ireland). The filtered solution was stored at $-20{ }^{\circ} \mathrm{C}$ in $1.0 \mathrm{ml}$ aliquots in sterile $1.5 \mathrm{ml}$ polystyrene Eppendorf tubes (Eppendorf, Mississauga, Canada). Each aliquot was thawed and warmed to $37{ }^{\circ} \mathrm{C}$ prior to use.

\section{Sperm freezing and thawing}

Both epididymides and vasa deferentia from male mice were removed and transferred to a $35 \mathrm{~mm}$ petri dish (Falcon 351008, Becton-Dickinson, NJ, USA) containing $1 \mathrm{ml} \mathrm{CPA}$ pre-stored in an incubator at $37{ }^{\circ} \mathrm{C}, 5 \%$ $\mathrm{CO}_{2}$. They were then pierced eight to ten times using sterile forceps allowing spermatozoa to swim out. Each vas deferens was then gently compressed along its length to expel residual spermatozoa with fine-tipped sterile forceps. The CPA with spermatozoa was then incubated for $10 \mathrm{~min}$ at $37^{\circ} \mathrm{C}$. After incubation, debris and tissue was manually removed and the sperm-CPA sample was distributed as $100 \mu \mathrm{l}$ aliquots into four cryovials (1.8-cC Nunc cryotubes; Nunc Cryotubes, Roskilde, Denmark) using wide pipette tips. Cooling rate was automatically controlled according to Songsasen \& Leibo (1997b). The cryovials were placed into a controlled-rate freezer (Thermo Forma 7452, Marietta, Ohio, USA) at $20{ }^{\circ} \mathrm{C}$. After $10 \mathrm{~min}$ in the freezer, the cryovials were cooled at $5{ }^{\circ} \mathrm{C} / \mathrm{min}$ to $+4{ }^{\circ} \mathrm{C}$ and held for $3 \mathrm{~min}$. The samples were cryopreserved without seeding. Sperm samples were cooled directly from $+4{ }^{\circ} \mathrm{C}$ at $20{ }^{\circ} \mathrm{C} / \mathrm{min}$ to $-100{ }^{\circ} \mathrm{C}$ and finally were plunged into liquid nitrogen $\left(\mathrm{LN}_{2}\right)$. Sperm freezing for each CPA group was replicated six times by using B6129SF1 mice (Table 1).

The sperm-CPA samples were separately distributed as $100 \mu \mathrm{l}$ aliquots into eight labeled 1.8-cc cryovials by using wide pipette tips.

For manual rate freezing, a styrofoam box was used measuring $20.5 \mathrm{~cm}$ (length) $\times 20.5 \mathrm{~cm}$ (width) $\times 20 \mathrm{~cm}$ (depth). It was filled to $2.5 \mathrm{~cm}$ from the bottom with $\mathrm{LN}_{2}$. Cryovials containing sperm-CPA were placed into a rack at $2 \mathrm{~cm}$ above the surface of $\mathrm{LN}_{2}$ exposing them to $\mathrm{LN}_{2}$ vapor (approximately $-120{ }^{\circ} \mathrm{C}$ ) for $10 \mathrm{~min}$ at a cooling rate of $20-40{ }^{\circ} \mathrm{C} / \mathrm{min}$. Sperm-CPA samples were then plunged directly into $\mathrm{LN}_{2}$ for storage. One frozen-thawed sperm sample was analyzed for sperm-assessment parameters and recorded prior to thawing and in vitro fertilization. Sperm freezing for each CPA group was replicated between 6 and 15 times using different mice (Tables 2 and 3). Samples were rapidly thawed by transferring them from $\mathrm{LN}_{2}$ into a $37^{\circ} \mathrm{C}$ water bath for 2 min until the ice melted.

\section{Sperm analysis}

\section{Progressive motility}

Progressive motility of sperm samples was determined using a Makler counting chamber (Sefi-Medical Instruments, Haifa, Israel) according to World Health Organization (WHO 1999) guidelines. Frozen sperm samples were diluted 1:4 or 1:6 with Human Tubal Fluid (HTF; Quinn et al. 1985) depending on sperm cell concentration. After 15-min incubation of frozen

Table 1 Post-thaw progressive motility and membrane integrity results for B6129SF1 mouse sperm using raffinose alone and or various combinations of permeating cryoprotectants under the same molar or same osmotic pressure $(n=6$; mean \pm s.E.).

\begin{tabular}{|c|c|c|c|}
\hline Type of CPA & Osmotic pressure (mOsm/l) & Progressive motility $(\%)$ & Intact membrane $(\%)$ \\
\hline $0.3 \mathrm{M}=$ raffinose $0.3 \mathrm{M}+$ skim milk (SM) & $470-490$ & $11.1 \pm 1.6^{\mathrm{b}, \mathrm{c}}$ & $27.9 \pm 1.6^{\mathrm{a}}$ \\
\hline $0.3 \mathrm{M}=$ raffinose $0.2 \mathrm{M}+$ glucose $0.1 \mathrm{M}+\mathrm{SM}$ & $430-450$ & $13.6 \pm 2.1^{\mathrm{a}, \mathrm{b}}$ & $25.8 \pm 4.3^{\mathrm{a}}$ \\
\hline $0.3 \mathrm{M}=$ raffinose $0.2 \mathrm{M}+$ fructose $0.1 \mathrm{M}+\mathrm{SM}$ & $430-450$ & $19.2 \pm 2.3^{\mathrm{a}}$ & $29.1 \pm 1.5^{\mathrm{a}}$ \\
\hline $0.3 \mathrm{M}=$ raffinose $0.2 \mathrm{M}+$ propylene glycol $0.1 \mathrm{M}+\mathrm{SM}$ & $430-450$ & $9.55 \pm 2.1^{\mathrm{b}, \mathrm{c}, \mathrm{e}}$ & $12.9 \pm 0.2^{\mathrm{b}}$ \\
\hline $0.3 \mathrm{M}=$ raffinose $0.2 \mathrm{M}+$ ethylene glycol $0.1 \mathrm{M}+\mathrm{SM}$ & $430-450$ & $11.9 \pm 1.9^{\mathrm{b}, \mathrm{c}}$ & $16.9 \pm 1.9^{\mathrm{b}, \mathrm{d}}$ \\
\hline $0.3 \mathrm{M}=$ raffinose $0.2 \mathrm{M}+$ glycerol $0.1 \mathrm{M}+\mathrm{SM}$ & $430-450$ & $14.2 \pm 3.1^{\mathrm{a}, \mathrm{b}}$ & $26.1 \pm 2.8^{\mathrm{a}}$ \\
\hline $0.3 \mathrm{M}=$ raffinose $0.2 \mathrm{M}+$ sodium pyruvate $0.1 \mathrm{M}+\mathrm{SM}$ & $430-450$ & $6.9 \pm 2.1^{\mathrm{c}, \mathrm{d}, \mathrm{e}}$ & $13.8 \pm 0.5^{b}$ \\
\hline Raffinose $0.2 \mathrm{M}+$ glucose $280 \mathrm{mg}+\mathrm{SM}$ & $470-490$ & $12.8 \pm 1.7^{\mathrm{a}, \mathrm{b}}$ & $31.6 \pm 2.1^{\mathrm{a}}$ \\
\hline Raffinose $0.2 \mathrm{M}+$ fructose $280 \mathrm{mg}+\mathrm{SM}$ & $470-490$ & $16.1 \pm 1.5^{\mathrm{a}, \mathrm{b}}$ & $25.6 \pm 0.4^{\mathrm{a}, \mathrm{d}}$ \\
\hline Raffinose $0.2 \mathrm{M}+$ propylene glycol $133 \mu \mathrm{I}+\mathrm{SM}$ & $470-490$ & $3.7 \pm 0.5^{\mathrm{d}}$ & $14.1 \pm 1.1^{\mathrm{b}}$ \\
\hline Raffinose $0.2 \mathrm{M}+$ ethylene glycol $98.7 \mu \mathrm{l}+\mathrm{SM}$ & $470-490$ & $5.6 \pm 0.5^{\mathrm{c}, \mathrm{d}, \mathrm{e}}$ & $15.3 \pm 1.3^{\mathrm{b}}$ \\
\hline Raffinose $0.2 \mathrm{M}+$ glycerol $128.8 \mu \mathrm{l}+\mathrm{SM}$ & $470-490$ & $12.9 \pm 1.9^{\mathrm{a}, \mathrm{b}}$ & $28.2 \pm 2.1^{\mathrm{a}}$ \\
\hline Raffinose $0.2 \mathrm{M}+$ sodium pyruvate $120 \mathrm{mg}+\mathrm{SM}$ & $470-490$ & $7.1 \pm 1.5^{\mathrm{e}}$ & $22.5 \pm 3.0^{\mathrm{a}, \mathrm{b}}$ \\
\hline Skim milk (no. of $\mathrm{CPA}=$ negative control) & 85 & $0.1 \pm 0.08^{f}$ & $1.5 \pm 0.2^{\mathrm{e}}$ \\
\hline
\end{tabular}

$n$, number of replicated experiment. a-f: $P<0.05$; different superscripts within column indicate significant differences. 
Table 2 Post-thaw progressive motility results for tested outbred, hybrid, and inbred strains of mice using alone or combined permeating and nonpermeating cryoprotectants (mean \pm s.e.).

\begin{tabular}{|c|c|c|c|c|c|c|}
\hline \multirow[b]{2}{*}{ Type of CPA } & \multicolumn{6}{|c|}{ Progressive motility (\%) } \\
\hline & CD-1 $(n=10)$ & C3B6F1 $(n=8)$ & B6129SF1 $(n=10)$ & C57BL/6 $(n=15)$ & $129 S(n=8)$ & $\mathrm{DBA}(n=8)$ \\
\hline Raffinose $0.3 \mathrm{M}$ & $24.3 \pm 2.3^{b}$ & $20.5 \pm 3.4^{\mathrm{d}, \mathrm{e}}$ & $21.8 \pm 3.2^{\mathrm{d}}$ & $3.4 \pm 1.2^{d}$ & $1.5 \pm 1.3^{\mathrm{d}}$ & $27.6 \pm 8.2^{\mathrm{C}}$ \\
\hline Raffinose $0.2 \mathrm{M}$ & $17.9 .0 \pm 2.4^{b}$ & $13.3 \pm 0.6^{\mathrm{e}}$ & $16.3 \pm 1.7^{\mathrm{d}}$ & $11.1 \pm 4.7^{\mathrm{C}}$ & $7.5 \pm 4.3^{\mathrm{C}}$ & $19.9 \pm 6.5^{\mathrm{c}}$ \\
\hline Raffinose $0.3 \mathrm{M}+$ Fru. $0.1 \mathrm{M}$ & $33.2 \pm 2.7^{\mathrm{a}}$ & $32.7 \pm 1.7^{\mathrm{C}}$ & $34.9 \pm 2.3^{\mathrm{C}}$ & $12.1 \pm 2.1^{\mathrm{C}}$ & $9.9 \pm 2.2^{\mathrm{C}}$ & $26.6 \pm 6.4^{\mathrm{c}}$ \\
\hline Raffinose $0.3 \mathrm{M}+$ Gly. $0.1 \mathrm{M}$ & $25.1 \pm 5.3^{a, b}$ & $27.14 \pm 2.4^{\mathrm{c}, \mathrm{d}}$ & $22.1 \pm 3.1^{\mathrm{d}}$ & $13.7 \pm 3.7^{\mathrm{c}}$ & $9.7 \pm 1.3^{c}$ & $24.5 \pm 6.6^{\mathrm{C}}$ \\
\hline
\end{tabular}

Osmotic pressure: 0.3 MRaf.=470-490 mOsm/l, 0.2 MRaf.=330-350 mOsm/l, 0.3 MRaf.+0.1 M Fru. or 0.3 M Raf. +0.1 MGly.=600-620 mOsm/l. $n=$ number of replicated experiment. a, b: $P<0.05 ; \mathrm{c}-\mathrm{e}, \mathrm{c}, \mathrm{d}: P<0.01$; different superscripts within column indicate significant differences.

sperm-CPA with HTF in a $37{ }^{\circ} \mathrm{C}$ water bath, $10 \mu$ of sperm-CPA sample was placed into a heated $\left(37^{\circ} \mathrm{C}\right)$ Makler counting chamber and evaluated for progressive motility of sperm. The number of motile and nonmotile spermatozoa was quantified by counting at least six predetermined fields (sequences) with a minimum of 200 spermatozoa. The routine sperm analysis was performed using an inverted phase contrast microscope (Zeiss, Axiovert 100; Zeiss, Oberkochen, Germany) with $10 \times$ magnification.

\section{Plasma membrane integrity}

Cell plasma membrane integrity was evaluated by the fluorescent staining method for sperm viability (Live/ Dead Sperm Viability Kit, Molecular Probes Inc., Eugene, OR, USA) according to manufacturer's guidelines. This vital stain contains two nucleic acid dyes: (1) SYBR-14 that permeates intact plasma membrane causing viable spermatozoa to fluoresce green and (2) propidium iodide that permeates only damaged plasma membrane, causing nonviable spermatozoa to fluoresce red. Stain was prepared according to Songsasen \& Leibo (1997b). After staining, $10 \mu \mathrm{l}$ of sperm sample was placed on a microscope slide covered with a cover slip and observed under a fluorescence microscope (Zeiss Model IM35, filter set 487709; excitation filter 450-490 nm). For each mouse, 200 spermatozoa were counted on each slide.

\section{DNA analysis}

DNA analysis was performed as described by Larson et al. (2000) and Traina et al. (2003). Briefly, fresh sperm cells were expelled from the isolated vas deferens into $1 \mathrm{ml}$ of TNA $(0.15 \mathrm{M} \mathrm{NaCl}, 0.01 \mathrm{M}$ Tris- $\mathrm{HCl}, 0.001 \mathrm{M}$ EDTA, pH 7.4) using watchmaker's forceps. After 15-min incubation, sperm samples were filtered through a $70 \mu \mathrm{m}$ nylon mesh and were counted to determine sperm concentration. From each fresh sperm sample, $1-2 \times 10^{6}$ cells were taken to a $15 \mathrm{ml}$ conical tube and a pellet was prepared after centrifugation at $300 \mathrm{~g}$ for $4 \mathrm{~min}$. Frozen sperm samples were archived in $\mathrm{LN}_{2}$ for 12 weeks prior to DNA analysis. Frozen-thawed sperm aliquots $(0.1 \mathrm{ml})$ were mixed with $1 \mathrm{ml}$ TNA and incubated for $10 \mathrm{~min}$ in an incubator at $37{ }^{\circ} \mathrm{C}, 5 \%$ $\mathrm{CO}_{2}$, then the solution was centrifuged at $300 \mathrm{~g}$ for $4 \mathrm{~min}$, the pellet re-suspended in $0.2 \mathrm{ml} \mathrm{TNA}$, and then mixed with $0.4 \mathrm{ml}$ acid-detergent solution $(0.1 \%$ Triton $X-100,0.15 \mathrm{M} \mathrm{NaCl}$, and 0,08 N HCL, pH 1.2). After $30 \mathrm{~s}$, the cells were stained by adding $1.2 \mathrm{ml}$ of a solution containing $6 \mu \mathrm{g} / \mathrm{ml}$ of Acridine Orange (AO; Molecular Probes Inc.) in staining buffer $(0.1 \mathrm{M}$ citric acid, $0.2 \mathrm{M}$ $\mathrm{Na}_{2} \mathrm{HPO}$, $1 \mathrm{mM}$ EDTA, $0.15 \mathrm{M} \mathrm{NaCl}$, pH 6). When excited with blue light $\mathrm{AO}$ intercalated into doublestranded DNA fluoresces green. AO associated with single-stranded DNA emits red fluorescence. Abnormal sperm chromatin structure was measured by flow cytometry (FCM), on a cell-by-cell basis, and expressed as green (native DNA) to red (denatured, single-stranded DNA) AO fluorescence intensity shift using an index called $\alpha \mathrm{T}$. Alpha-T represents the ratio of red to total (red+green) fluorescence. Normal, native chromatin remains structurally sound and produces a narrow $\alpha \mathrm{T}$ distribution. DNA in sperm with abnormal chromatin structure has increased red fluorescence, thereby

Table 3 Post-thaw plasma membrane integrity results for tested outbred, hybrid, and inbred strains of mice using alone or combined permeating and nonpermeating cryoprotectants (mean \pm S.E.).

\begin{tabular}{|c|c|c|c|c|c|c|}
\hline \multirow[b]{2}{*}{ Type of CPA } & \multicolumn{6}{|c|}{ Intact membrane (\%) } \\
\hline & CD-1 $(n=10)$ & C3B6F1 $(n=8)$ & B6129SF1 $(n=10)$ & $\mathrm{C} 57 \mathrm{BL} / 6(n=15)$ & $129 S(n=8)$ & DBA $(n=8)$ \\
\hline Raffinose $0.3 \mathrm{M}$ & $38.6 \pm 3.1^{\mathrm{a}, \mathrm{b}}$ & $33.2 \pm 5.3^{\mathrm{a}, \mathrm{b}}$ & $36.0 \pm 2.4^{\mathrm{a}, \mathrm{b}}$ & $20.8 \pm 5.8^{\mathrm{a}}$ & $18.7 \pm 3.5^{\mathrm{a}}$ & $38.0 \pm 4.5^{\mathrm{a}}$ \\
\hline Raffinose $0.2 \mathrm{M}$ & $28.3 \pm 1.9^{\mathrm{b}}$ & $24.0 \pm 2.8^{\mathrm{b}}$ & $27.9 \pm 1.2^{\mathrm{b}}$ & $23.0 \pm 7.3^{\mathrm{a}}$ & $25.0 \pm 6.1^{\mathrm{a}}$ & $27.3 \pm 3.9^{a}$ \\
\hline Raffinose $0.3 \mathrm{M}+$ Fru. $0.1 \mathrm{M}$ & $40.3 \pm 2.3^{\mathrm{a}}$ & $39.7 \pm 2.4^{\mathrm{a}}$ & $39.3 \pm 3.9^{\mathrm{a}}$ & $25.4 \pm 4.7^{\mathrm{a}}$ & $22.2 \pm 4.5^{\mathrm{a}}$ & $33.6 \pm 5.3^{\mathrm{a}}$ \\
\hline Raffinose $0.3 \mathrm{M}+$ Gly. $0.1 \mathrm{M}$ & $35.3 \pm 2.6^{a, b}$ & $36.9 \pm 3.9^{\mathrm{a}}$ & $38.0 \pm 4.8^{\mathrm{a}, \mathrm{b}}$ & $28.6 \pm 2.1^{\mathrm{a}}$ & $25.8 \pm 3.6^{\mathrm{a}}$ & $35.4 \pm 4.4^{\mathrm{a}}$ \\
\hline
\end{tabular}

Osmotic pressure: $0.3 \mathrm{MRaf} .=470-490 \mathrm{mOsm} / \mathrm{l}, 0.2 \mathrm{MRaf} .=330-350 \mathrm{mOsm} / \mathrm{l}, 0.3 \mathrm{MRaf} .+0.1 \mathrm{M}$ Fru. or 0.3 M Raf. $+0.1 \mathrm{MGly} .=600-620 \mathrm{mOsm} / \mathrm{l}$. ( $n=$ number of replicated experiment). a and b: $P<0.05$; different superscripts within column indicate significant differences. 
producing a broader $\alpha \mathrm{T}$ distribution. Cells were analyzed using the FACSCalibur flow cytometer (Becton Dickinson, Serial no. E0939, Biosciences, NJ, USA). Green fluorescence was measured between 515 and $545 \mathrm{~nm}$ band pass filter and red fluorescence using an LP670 nm long pass filter. The two colors were separated by a $560 \mathrm{~nm}$ dichroic filter. Data was stored in list-mode at 10 bit resolution. A total of $5 \times 10^{4}$ gated events were accumulated for each measurement. A gate was set on FL1 vs FL3 to exclude debris. Flowjo software (Version 4.0, Tree Star, Inc. Ashland, OR, USA) was used to analyze values of $\alpha$ T. Fresh sperm from B6129SF1 mice sonicated for $5 \mathrm{~min}$ using a sonicator (power rate 5, pulsar duty cycle 75\%/s; Ultrasonic Processor XL Sonicator, Hert Systems, Farmingdale, NY, USA) adjusted to increase DNA fragmentation was used as positive control for the sperm chromatin structure assay (SCSA) system (Fig. 1).

\section{In vitro fertilization}

In vitro fertilization was performed as modified by Sztein et al. (2000). Four to five-week-old B6C3F1 hybrid mice were superovulated by i.p. injection of $0.5 \mathrm{IU}$ of pregnant mare serum gonadotrophin (PMSG) followed by $0.5 \mathrm{IU}$ of human chorionic gonadotrophin (hCG) $48 \mathrm{~h}$ later. Female mice were sacrificed by cervical dislocation $14 \mathrm{~h}$ after the hCG injection and their oviducts removed into a plastic culture dish containing $2 \mathrm{ml}$ of HTF medium. The cumulus-oocyte complexes were released from the ampulla into the HTF by rupturing with fine sterile forceps, and then placed into a $250 \mu \mathrm{l} \mathrm{HTF}$ fertilization drop. Dishes with HTF drops for fertilization and culture were overlaid with mineral oil for sealing, and then placed overnight in a modular incubator chamber at $37{ }^{\circ} \mathrm{C}$ in a humidified atmosphere of $5 \% \mathrm{CO}_{2}$. IVF drop for C3B6F1 sperm+B6C3F1 oocyte combinations was used per three oocyte donors with a low concentration, $5 \times 10^{5}$ of progressively motile sperm per milliliter of fresh or frozen sperm.

Frozen sperm samples were thawed in a $37{ }^{\circ} \mathrm{C}$ water bath for $3 \mathrm{~min}$ and centrifuged at $3000 \mathrm{~g}$ (Mikro 20, D-78532, Tuttlingen, Germany) for $4 \mathrm{~min}$. The supernatant was discarded and replaced with $50 \mu$ l of HTF. The sperm samples were re-suspended by gently tapping of the tube and then incubated for 20 min at $37{ }^{\circ} \mathrm{C}$ to allow a minimal 'swim up'. A $40 \mu \mathrm{l}$ aliquot after incubation was taken for the IVF assay from each sperm sample. The fertilization drop was maintained for $4 \mathrm{~h}$ at $5 \% \mathrm{CO}_{2}$ in an incubator and then the oocytes were washed with HTF to eliminate excess sperm. The inseminated oocytes were cultured overnight in a $100 \mu \mathrm{l}$ drop of HTF. The next morning, the number of two-cell embryos was scored, and transferred to a $100 \mu \mathrm{l}$ drop of KSOM/AA medium
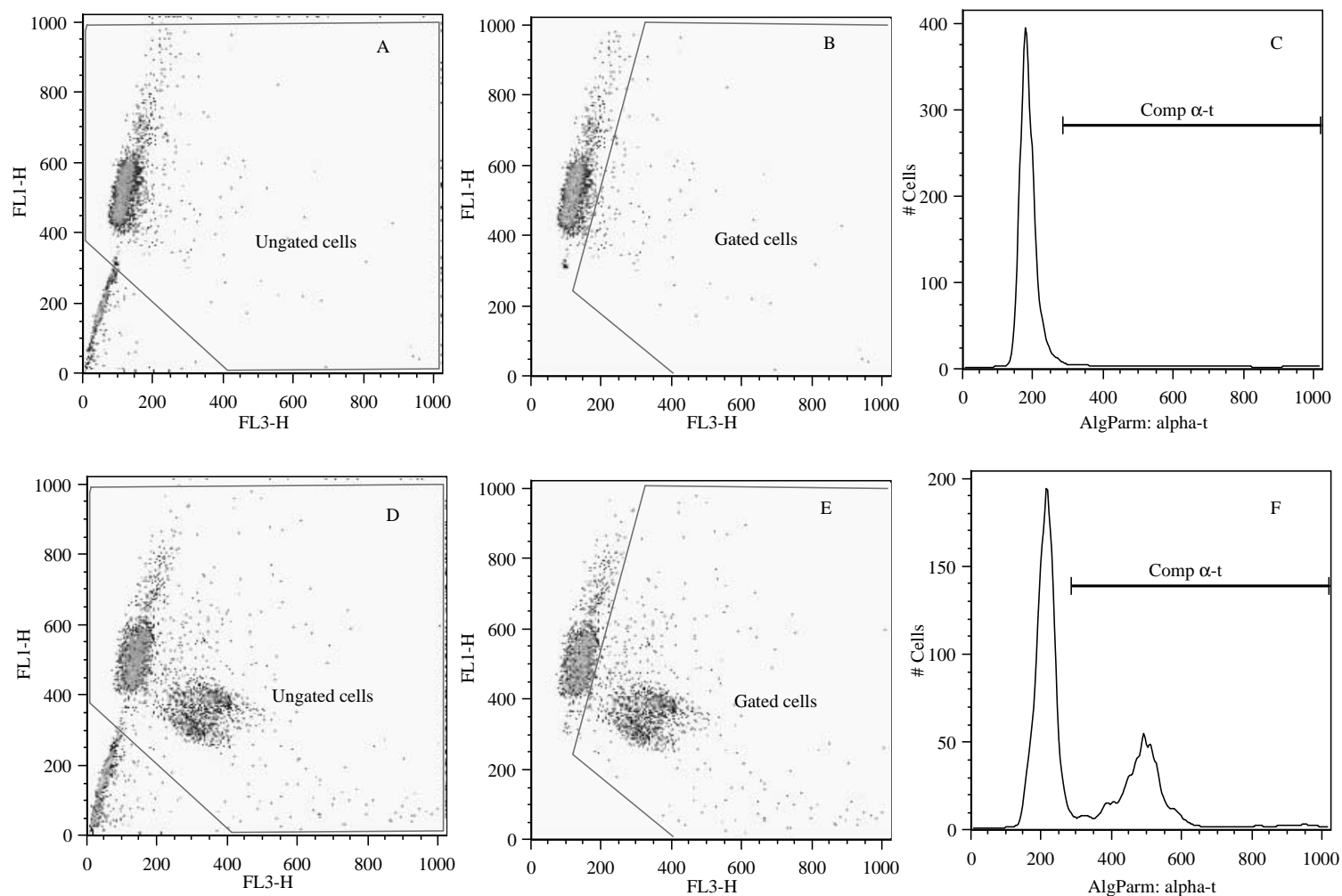

Figure 1 SCSA data with cytogram and histogram $(\alpha-t)$ showing the effects of sonication in unsonicated B6129SF1 fresh mouse sperm (control sample; A, B, and C) and with sonication (D, E, and F). Cells (gated cells : comp- $\alpha \mathrm{T}$ ) outside the main population have a larger ratio of red:green fluorescence, indicative of abnormal chromatin structure. 
(Ho et al. 1995) for in vitro embryo development to the blastocyst stage. This IVF procedure was replicated three or four times for fresh and frozen sperm using different males for each strain of mice evaluated.

\section{Zona-thinned oocytes for in vitro fertilization}

To test the in vitro fertilization rate and in vitro embryo development rate to blastocyst of C57BL/6 sperm IVF zona-thinned B6C3F1 oocytes were used. A minimum count of $1 \times 10^{6}$ progressively motile sperm per milliliter was used in combination with $\mathrm{C} 57 \mathrm{BL} / 6$ fresh or frozen sperm + B6C3F1 oocytes. To account for any parthenogenetic effects on oocytes in the zona-thinned group, cleaved parthenogenetic oocytes were identified and removed from culture according to Nagy et al. (2002).

The oocyte-cumulus complexes were collected from superovulated C3B6F1 mice. Cumulus cells were removed by using $0.05 \mathrm{mg} / \mathrm{ml}$ hyaluronidase (Sigma; $\mathrm{H}$-3506) for $5 \mathrm{~min}$ in HTF medium. After washing the oocytes with HTF, zona thinning was performed using zona tyrode solution containing $0.8 \mathrm{~g} \mathrm{NaCl}, 0.02 \mathrm{~g} \mathrm{KCl}$, $0.024 \mathrm{~g} \mathrm{CaCl}_{2} 2 \mathrm{H}_{2} \mathrm{O}, 0.301 \mathrm{~g} \mathrm{MgCl}_{2} 6 \mathrm{H}_{2} \mathrm{O}, 0.1$ g Glucose, $0.4 \mathrm{~g}$ polyvinylpyrolidone (PVP) in $100 \mathrm{ml}$ water $(\mathrm{pH} 3.0)$. Oocytes were exposed for $45 \mathrm{~s}$ to the acid tyrode solution and washed three times with fresh HTF media prior to use.

\section{Statistical analyses}

Statistical analyses were performed using Graphpad Prism version 3.0 software (Graphpad software, San Diago, CA, USA). Post-thaw sperm assessment parameter results for DNA integrity, in vitro fertilization rate, and in vitro embryo development rate to blastocyst were evaluated for significance using repeated-measures one-way ANOVA (Tables 1-6). The Dunnett multiple-comparison test was used to compare differences among groups studied.

\section{Results}

\section{Experiment 1}

The greatest progressive motility of B6129SF1 sperm was obtained with the combination of $0.2 \mathrm{M}$ raffinose+
$0.1 \mathrm{M}$ fructose $(430-450 \mathrm{mOsm})$ compared to $0.3 \mathrm{M}$ raffinose alone $(P<0.05)$. However, there were no significant differences in sperm membrane integrity between the groups with CPA and the negative control. The combination of $0.2 \mathrm{M}$ raffinose $+0.1 \mathrm{M}$ glycerol significantly improved progressive motility and plasma membrane integrity compared to other polyols, such as prophylenglycol or ethylenglycol, propylene glycol, ethylene glycol, glycerol, or sodium pyruvate with osmotic pressure between 430 and $490 \mathrm{mOsm}$ $(P<0.05$, Table 1$)$. All combinations of CPA in all groups after thawing improved progressive motility and membrane integrity when compared with the negative control group (no CPA; $P<0.05$; Table 1).

\section{Experiment 2}

Raffinose alone, and raffinose combined with fructose and glycerol were evaluated by using sperm from several strains of mice selected for this study (Tables 2 and 3). The optimal molar concentrations were determined to be 0.2 and $0.3 \mathrm{M}$ raffinose in outbred, hybrid, and inbred strains of mice.

The results of comparing different combinations and concentrations of CPA are presented in Tables 2 and 3. Combination of $0.3 \mathrm{M}$ raffinose $+0.1 \mathrm{M}$ fructose had the highest progressive motility rates when compared with $0.3 \mathrm{M}$ raffinose alone and $0.3 \mathrm{M}$ raffinose $+0.1 \mathrm{M}$ glycerol groups in CD-1, C3B6F1, and B6129SF1 mice $(P<0.05-0.01)$. There were no significant differences in rates of DNA fragmentation in frozen-thawed sperm from CD-1, C3B6F1, B6129SF1, and DBA mice when compared with the CPA control groups (Table 4). A $0.2 \mathrm{M}$ concentration of raffinose in CPA solution had a significant beneficial impact on the progressive motility and membrane integrity of sperm from C57BL6 and 129S mice when compared with $0.3 \mathrm{M}$ raffinose alone after freezing and thawing. Additionally, $0.2 \mathrm{M}$ raffinose+ $0.1 \mathrm{M}$ glycerol and $0.2 \mathrm{M}$ raffinose $+0.1 \mathrm{M}$ fructose in C57BL/6 and 129S mice provided for the highest progressive motility when compared with $0.3 \mathrm{M}$ raffinose alone $(P<0.001)$, but did not significantly affect membrane integrity. Post-thaw C57BL/6 and $129 \mathrm{~S}$ inbred sperm had a higher DNA fragmentation rate when

Table 4 Post-thaw DNA integrity results for mouse sperm using combined permeating and nonpermeating cryoprotectants with skim milk on selected strains $(n=8$; mean \pm S.E.).

\begin{tabular}{|c|c|c|c|c|c|c|c|}
\hline \multirow[b]{2}{*}{ Type of CPA } & \multicolumn{4}{|c|}{ Fragmented DNA (\%) } & \multirow[b]{2}{*}{ Type of CPA } & \multicolumn{2}{|c|}{ Fragmented DNA (\%) } \\
\hline & CD-1 & C3B6F1 & B6129SF1 & DBA & & $\mathrm{C} 57 \mathrm{BL} / 6$ & $129 S$ \\
\hline Fresh sperm & $1.6 \pm 0.2^{b}$ & $1.4 \pm 0.6^{\mathrm{d}}$ & $1.1 \pm 0.1^{f}$ & $3.7 \pm 1.1^{\mathrm{h}}$ & Fresh sperm & $3.2 \pm 0.7^{1}$ & $4.8 \pm 1.3^{\circ}$ \\
\hline Raffinose $0.3 \mathrm{M}$ & $6.1+1.1^{\mathrm{a}}$ & $6.8+1.3^{c}$ & $8.9+1.6^{\mathrm{e}}$ & $9.4+3.9^{g}$ & Raffinose $0.3 \mathrm{M}$ & $34.1+1.4^{\mathrm{i}}$ & $25.4+2.2^{\mathrm{m}}$ \\
\hline Raffinose $0.2 \mathrm{M}$ & $7.2 \pm 1.6^{\mathrm{a}}$ & $8.1 \pm 0.6^{\mathrm{c}}$ & $10.4 \pm 0.9^{\mathrm{e}}$ & $11.9 \pm 1.2^{\mathrm{g}}$ & Raffinose $0.2 \mathrm{M}$ & $30.7 \pm 4.9^{\mathrm{i}, \mathrm{j}}$ & $19.4 \pm 2.4^{\mathrm{m}, \mathrm{n}}$ \\
\hline Raf. $0.3 \mathrm{M}+$ Fru. $0.1 \mathrm{M}$ & $5.1 \pm 1.3^{\mathrm{a}}$ & $5.7 \pm 0.4^{\mathrm{C}}$ & $9.3 \pm 2.1^{\mathrm{e}}$ & $10.8 \pm 2.1^{\mathrm{g}}$ & Raf. $0.2 \mathrm{M}+$ Fru. $0.1 \mathrm{M}$ & $22.5 \pm 1.9^{\mathrm{j}, \mathrm{k}}$ & $15.1 \pm 0.9^{n}$ \\
\hline Raf. $0.3 \mathrm{M}+$ Gly. $0.1 \mathrm{M}$ & $6.5 \pm 0.6^{a}$ & $6.4 \pm 0.9^{c}$ & $7.9 \pm 3.5^{\mathrm{e}}$ & $9.7 \pm 2.1^{\mathrm{g}}$ & Raf. $0.2 \mathrm{M}+$ Gly. $0.1 \mathrm{M}$ & $17.4 \pm 2.8^{\mathrm{k}}$ & $21.5 \pm 3.4^{\mathrm{m}, \mathrm{n}}$ \\
\hline
\end{tabular}

$n$, number of replicated experiment. a-O: $P<0.01$ : letters within columns indicate significant differences. Fragmented DNA (COMP $\alpha \mathrm{T})$ is the

$\%$ of sperm with abnormal chromatin. 
Table 5 In vitro fertilization rate and embryo development rate to blastocyst for C3B6F1 mouse sperm cryopreserved with different cryoprotectants.

\begin{tabular}{|c|c|c|c|c|c|}
\hline Sperm donor & Type of CPA & Type of sperm treatment & Number of oocytes & Number of 2-cell $(\%)$ & $\begin{array}{c}\text { Number of } \\
\text { blastocysts (\%) }\end{array}$ \\
\hline C3B6F1 & $\begin{array}{l}\text { No CPA } \\
0.3 \mathrm{MR}+\mathrm{SM} \\
0.3 \mathrm{MR}+0.1 \mathrm{MF}+\mathrm{SM}\end{array}$ & $\begin{array}{l}\text { Fresh } \\
\text { Frozen } \\
\text { Frozen }\end{array}$ & $\begin{array}{l}135 \\
152 \\
161\end{array}$ & $\begin{array}{l}97(71.8)^{\mathrm{a}} \\
33(21.7)^{\mathrm{c}} \\
57(35.4)^{\mathrm{b}}\end{array}$ & $\begin{array}{l}81(83.5)^{\mathrm{d}} \\
20(71.4)^{\mathrm{d}} \\
33(75.0)^{\mathrm{d}}\end{array}$ \\
\hline
\end{tabular}

a-d: $P<0.05$; Different superscripts within column indicate significant differences.

compared with CD-1, C3B6F1, B6129SF1, and inbred DBA mice (Table 4). Interestingly, both $0.2 \mathrm{M}$ raffinose+ $0.1 \mathrm{M}$ fructose and $0.2 \mathrm{M}$ raffinose $+0.1 \mathrm{M}$ glycerol combination in C57BL/ 6 or $129 \mathrm{~S}$ mice resulted in more robust sperm cell DNA integrity when compared with raffinose alone $(P<0.01)$. In other words, supplementation of CPA solution with glycerol or fructose showed a protective effect for DNA integrity against freezing damage in C57BL/6 and 129S mice $(P<0.01)$. The combination of $0.3 \mathrm{M}$ raffinose + skim milk resulted in increased values for progressive motility, membrane integrity, and a lower rate of DNA fragmentation after freezing in DBA mice $(P>0.05)$. Although DBA was one of the inbred strains, it showed the highest resistance to DNA damage during freezing when compared with C57BL/6 and 129S inbred mice. In addition, resistance to DNA damage during freezing in the strains of outbred and hybrid mice tested were significantly greater than C57BL/6 and $129 \mathrm{~S}$ inbred mice $(P<0.01)$. The cryopreservation process increased DNA fragmentation in all strains of outbred, hybrid, and inbred mice when compared with the fresh control sperm $(P<0.01$; Table 4).

\section{Experiment 3}

The combination of $0.3 \mathrm{M}$ raffinose $+0.1 \mathrm{M}$ fructose had a higher in vitro fertilization rate than $0.3 \mathrm{M}$ raffinose alone when compared with C3B6F1 oocytes fertilized with C3B6F1 fresh sperm $(P<0.05$; Table 5). However, there were no significant differences in embryo development rate to blastocyst between fresh C3B6F1 hybrid sperm using $0.3 \mathrm{M}$ raffinose alone or $0.3 \mathrm{M}$ raffinose+ $0.1 \mathrm{M}$ fructose. For the inbred $\mathrm{C} 57 \mathrm{BL} / 6$ strain, the results from experiment 3 further showed the efficiency of $0.2 \mathrm{M}$ raffinose $+0.1 \mathrm{M}$ glycerol combination in improving the in vitro fertilization rate and in vitro embryo development rate to blastocyst using C3B6F1 oocytes and
C57BL/6 sperm (Table 6). A measure of $0.3 \mathrm{M}$ raffinose alone resulted in lower in vitro fertilization rate when compared with fresh C56BL/ 6 sperm or $0.2 \mathrm{M}$ raffinose+ 0.1 M glycerol combination $(P<0.05)$. On the other hand, the combination of $0.1 \mathrm{M}$ glycerol $+0.2 \mathrm{M}$ raffinose significantly improved in vitro fertilization rate for frozen C57BL/6 sperm $(P<0.05)$. In addition, this CPA combination had a lower DNA fragmentation rate that correlated with an increased in vitro embryo development rate to blastocyst when compared with $0.3 \mathrm{M}$ raffinose alone for frozen $\mathrm{C} 57 \mathrm{BL} / 6$ sperm.

\section{Discussion}

Investigation into the effects of variable combinations and concentrations of cryoprotectants on sperm quality is critical to generate more efficient techniques for mouse sperm cryopreservation.

The results of the first set of experiments from this study show that the type (chemical structure) of cryoprotectant and combination of permeating and nonpermeating cryoprotectants are important factors that effect the progressive motility and plasma membrane integrity of B6129S1 hybrid mouse sperm during freezing and thawing. Supplementation of glycerol or fructose to raffinose increased post-freezing progressive motility when compared with raffinose alone or combined permeating cryoprotectants (i.e. glucose or ethylene glycol) in B6129SF1 mice. The beneficial effects of using combined permeating and nonpermeating cryoprotectants in this study concur with previous reports in the literature that showed combinations of $18 \%$ raffinose and $1.75 \%$ glycerol (Tada et al. 1990), 10\% raffinose and 5\% glycerol (Yokoyama et al. 1990), and 6\% glycerol plus trehalose (Storey et al. 1998) provided for the highest motility and plasma membrane integrity rates after sperm freezing and thawing.

Table 6 In vitro fertilization rate and embryo development rate to blastocyt for C57BL/6 mouse sperm cryopreserved with different cryoprotectants.

\begin{tabular}{|c|c|c|c|c|c|}
\hline Sperm donor & Type of CPA & Type of sperm treatment & Number of oocytes & Number of 2-cell (\%) & $\begin{array}{c}\text { Number of } \\
\text { blastocysts (\%) }\end{array}$ \\
\hline \multirow[t]{3}{*}{$\mathrm{C} 57 \mathrm{BL} / 6$} & No CPA & Fresh & 142 & $97(68.3)^{\mathrm{a}}$ & $76(78.3)^{d}$ \\
\hline & $0.3 \mathrm{MR}+\mathrm{SM}$ & Frozen & 362 & $78(21.5)^{\mathrm{C}}$ & $15(19.2)^{f}$ \\
\hline & 0.2 M R +0.1 M Gly + SM & Frozen & 359 & $139(38.7)^{b}$ & $56(40.2)^{\mathrm{e}}$ \\
\hline
\end{tabular}

a-f: $P<0.05$; different superscripts within column indicate significant differences. 
The values for sperm progressive motility and membrane integrity reported in the second set of experiments from this study vary according to the molar concentration of CPA and mouse strain used. The use of raffinose alone or combined with permeating fructose or glycerol provided improved progressive motility and plasma membrane integrity when compared with molar concentration of raffinose $(0.2$ or $0.3 \mathrm{M})$. Koshimoto \& Mazur (2002) pointed out that combinations of raffinose, sucrose, and glucose in PBS did not improve normalized motility when compared with raffinose alone under the same osmotic pressure (410$427 \mathrm{mOsm})$ or fixed at $18 \%(\mathrm{w} / \mathrm{v})$ in outbred ICR mouse sperm. A similar finding is presented in Tables 1 and 2 of the present study for the response of raffinose + glucose or fructose combination in B6129SF1 and CD-1 strains. However, Koshimoto \& Mazur (2002) also suggested that there is no special protection conferred by a particular sugar, and that protection against damage during freezing and thawing depends on the mass concentration of the sugar rather than its molar concentration. On the contrary, according to our results presented in Table 2, even though fructose $(M W=180.2)$ has the same molecular weight as glucose, it significantly increased post-thaw progressive motility. The beneficial effects and improved sperm-assessment parameters produced as a result of varying sugar types and CPA combination (i.e glycerol) have also been reported for ram (Molinia et al. 1994), bovine (Garcia \& Graham 1989), dog (Yildiz et al. 2000), and human sperm (Critser et al. 1988, McGonagle et al. 2002). The effectiveness of fructose on sperm motility in CD-1, C3B6F1, B6129SF1, C57BL/6, and 1295 mice can be explained by its relatively higher permeation rate across the cell plasma membrane and rapid metabolic processing in the cell when compared with other monosaccharides, such as glucose or galactose (Schwartz 1997).

The choice of sugar in the CPA formulation in the second set of experiments presented here had a significant impact on post-thaw mouse sperm motility in a strain-dependent manner. CD-1, C3B6F1, B6129SF1, and DBA sperm were frozen successfully using $0.3 \mathrm{M}$ raffinose alone or $0.3 \mathrm{M}$ raffinose $+0.1 \mathrm{M}$ fructose combination (Table 2). It has been previously reported that the same molar concentration of CPA (i.e. $0.3 \mathrm{M}$ raffinose) is not effective and does not equally preserve the sperm from some strains of mice, such as C57BL/6 and 129S when compared with hybrid and other inbred mice (Songsasen \& Leibo 1997a, Sztein et al. 2000, Sztein et al. 2001, Nishizono et al. 2004). Also C57BL/6 and $129 \mathrm{~S}$ sperm were frozen successfully using $0.2 \mathrm{M}$ raffinose $+0.1 \mathrm{M}$ fructose or glycerol combination (Table 2). It is also reasonable to assume that there can also be differences in sperm head or biochemical composition of sperm head membrane between C57BL/6 and 1295 and other outbred, hybrid, and inbred strains of mice. If a suitable CPA's molar concentration is not used, the biochemical membrane properties or differences in sperm head dimension may possibly induce cell death caused by intracellular or extracellular ice crystallization during freezing; resulting in inadequate dehydration and intracellular high-solute concentration. Also in the second set of experiments presented here, even though $0.3 \mathrm{M}$ raffinose alone had a lower osmolarity (470-490 mOsm) than $0.3 \mathrm{M}$ raffinose-0.1 M fructose combination (600-620 mOsm), this combination of sugar showed statistically higher progressive motility than $470-490$ mOsm group in CD-1, C3B6F1 and B6129SF1 mice. Willoughby et al. (1996) reported a critical osmolarity of 500 mOsm in anisotonic PBS for mouse sperm. However, Agca et al. (2002) recently reported that egg yolk and skim milk significantly protected sperm motility and extended its osmotic tolerance limit (150-600 mOsm) when compared with $\mathrm{NaCl}$, choline, or sucrose alone in ICR and B6C3F1 mice. Similar results using higher osmotic pressures were also found in this study.

DNA integrity of sperm is essential for accurate transmission of paternal genetic information. Normal condensation and stabilization of sperm chromatin in the nucleus followed by decondensation after sperm penetration and injection into the cytoplasm of the oocyte are pre-requisites for fertilization (Flaherty et al. 1995). The effects of cryopreservation on the integrity of the sperm nucleus are not well characterized. It is reported that the cryopreservation process of freezing and thawing can increase inappropriate chromatin condensation in human (Royere et al. 1988, Royere et al. 1991, Donnelly et al. 2001, Hammadeh et al. 2001), boar (Fraser \& Strzezek 2004), horse (Linfor \& Meyers 2002), and ram (Peris at al. 2004) sperm. Recently, Chohan et al. (2004) noted that normal chromatin packaging significantly decreases after the freeze-thawing procedure in human sperm. Likewise, the cryopreservation process in our studies significantly increased the rate of abnormal sperm DNA in all tested strains compared to the rate in fresh control sperm (Table 4). However, different from the results presented here, Jiang et al. (2005) reported that nuclear DNA of fresh or cryopreserved sperm using isotonic CZB-HEPES solution did not affect the level of DNA fragmentation in outbred Kunming mice. The discrepancy between our findings and this report may result from using isotonic CZB-HEPES solution as a cryoprotectant and a different strain of mice. The second set of experiments reported here showed that the sperm DNA integrity was significantly increased by the cryopreservation process in C57BL/6 and $129 \mathrm{~S}$ inbred mice, but was not affected by the freezing process in CD-1, C3B6F1, B6129SF1, and DBA strains of mice. This clearly implies that there are significant differences in resistance and susceptibility to DNA fragmentation between strains of outbred, hybrid, and inbred mice. In addition, supplementation of fructose or glycerol to raffinose not only protected 
progressive motility and membrane integrity, but also DNA integrity of frozen-thawed C57BL6 and 129S sperm when compared with raffinose alone. It is well known that cryoprotectants are essential for the survival of cells during cryopreservation and the most commonly used cryoprotectans are sugars and glycerol. Strauss et al. (1986) and Anchordoguy et al. (1987) showed that sugars have cryoprotective properties because they lower the Van der Waals interactions at the membrane hydrocarbon chains that enhance trans-membrane transfer (especially phospholipids). The exact mechanism of action for glycerol in protecting cells from freeze-thaw damage is not completely understood. However, it is known that glycerol is osmotically active and is slow to permeate membranes resulting in cell volume changes from both the addition of glycerol and water loss during the freeze-thaw cycle (Schneider \& Mazur 1984, Hammerstedt et al. 1990). Glycerol induces interdigitation of the two bilayer leaflets, altering membrane fluidity by increasing the order of the interior fatty acyl chains (Boggs \& Rangaraj 1985). The beneficial effects of fructose and glycerol on DNA integrity in our study may be related to the different interactions on the DNA defense mechanisms of fructose or glycerol during the cryopreservation process.

The impact of the chemical formulation and combinations of CPA on unassisted in vitro fertility rate and in vitro embryo development rate to blastocyst was evaluated by using $\mathrm{C} 3 \mathrm{~B} 6 \mathrm{~F} 1$ and $\mathrm{C} 57 \mathrm{BL} / 6$ sperm donors in the third set of experiments reported here (Tables 5 and 6). Our findings show that both inbred and hybrid fresh sperm had higher in vitro fertility rates and embryo development rates to blastocyst when compared with frozen-thawed sperm. These findings are consistent with previous reports on in vitro fertilization and in vitro embryo development rate to blastocyst of inbred strains previously reported (Niwa et al. 1980, Songsasen \& Leibo 1997a, Sztein et al. 2000). The combination of $0.3 \mathrm{M}$ raffinose $+0.1 \mathrm{M}$ fructose with IVF produced higher in vitro fertility rates than $0.3 \mathrm{M}$ raffinose alone and a lower in vitro fertility rate than C3B6F1 fresh sperm. However, there were no significant differences in embryo development rate to blastocyst between fresh sperm, $0.3 \mathrm{M}$ raffinose alone, or $0.3 \mathrm{M}$ raffinose $+0.1 \mathrm{M}$ fructose. Progressive motility is one of the most important criteria for fertilization potential of sperm (WHO 1999). Thus, higher fertilization results reported here that were obtained from the combination of $0.3 \mathrm{M}$ raffinose $+0.1 \mathrm{M}$ fructose in $\mathrm{C} 3 \mathrm{~B} 6 \mathrm{~F} 1$ mice may be related to their greater post-thaw progressive motility rate when compared with $0.3 \mathrm{M}$ raffinose alone (Tables 2 and 5). A similar correlation can be assumed between the combination of $0.2 \mathrm{M}$ raffinose $+0.1 \mathrm{M}$ glycerol due to the higher post-thaw progressive motility rate observed when compared with $0.3 \mathrm{M}$ raffinose alone in C57BL/6 mice (Tables 2 and 6). Recently, Nishizono et al. (2004) reported that using $0.3 \mathrm{M}$ raffinose-skim milk combination significantly increased the occurrence of abnormal or dysmporphic acrosome after the cryopreservation process in $\mathrm{C} 57 \mathrm{BL} / 6$ sperm, and reported a strong correlation between dysmorphic spermatozoa and fertilization rates. Unlike this report, our in vitro fertilization rate for $\mathrm{C} 57 \mathrm{BL} / 6$ mice using a combination of $0.2 \mathrm{M}$ raffinose $+0.1 \mathrm{M}$ glycerol can be related to the better protective effect of raffinoseglycerol-skim milk combination on sperm membrane compared to $0.3 \mathrm{M}$ raffinose-skim milk. Glycerol has previously been shown to be effective in protection against freezing membrane injuries in commonly used species of livestock (Parks \& Graham 1992, Curry 1995) and a combination of sucrose and glycerol successfully protects embryos from various mammalian species and also bull sperm (Honadel \& Killian 1988, De Leeuw et al. 1993) during cryopreservation. Classic cryobiology studies suggest the use of glycerol or any permeating additive to more efficiently protect cells from freezing injuries through colligative or solution effects (Mazur 1970). Therefore, using a CPA combination of glycerol and raffinose in $\mathrm{C} 57 \mathrm{BL} / 6$ spermatozoa may have a synergistic effect on the protection of sperm cell membranes (i.e. the acrosome), resulting in higher in vitro fertilization rates. The combination of $0.1 \mathrm{M}$ glycerol + $0.2 \mathrm{M}$ raffinose in the present studies protected sperm DNA integrity and significantly improved in vitro embryo development rate to blastocyst when compared with $0.3 \mathrm{M}$ raffinose alone in $\mathrm{C} 57 \mathrm{BL} / 6$ mice (Table 6). Decreases in fertilization rate and poor embryo implantation have been shown to be related to sperm DNA fragmentation (Hughes et al. 1996, Edwards \& Beard 1999). Likewise, Larson et al. (2000) and Tesarik et al. (2004) noted that chromatin abnormalities decrease late embryonic development after ICSI treatment with human sperm. Similarly, in the results presented here, higher rates of DNA fragmentation that were obtained using $0.3 \mathrm{M}$ raffinose significantly decreased embryo development rate to blastocyst when compared with fresh sperm and the combination of $0.1 \mathrm{M}$ glycerol $+0.2 \mathrm{M}$ raffinose in C57BL6 mice (Table 6). These results suggest that the chemical formulation of CPA is important and varies in its ability to protect the DNA material of sperm during cryopreservation, and that increased levels of DNA fragmentation significantly decreases embryo development rate to blastocyst in C57BL6 mice. Recently, Seli et al. (2004) also reported a negative correlation between DNA fragmentation and blastocyst development for human sperm.

In summary, the results obtained from the experiments reported here support conclusion that: (1) the type of monosaccaride sugar or polyols used in CPAs are an important factor for mouse sperm cryopreservation, (2) molar concentrations of nonpermeating raffinose sugar in CPA solution have a significant impact on spermassessment parameters in C57BL6 and 129S mice, (3) the cryopreservation process increases DNA fragmentation 
in all tested outbred, hybrid, and inbred strains of mice when compared with fresh control, (4) the resistance of sperm DNA to damage during freezing and thawing of inbred strains appears to be strain dependent, (5) C57BL/6 and 129S mice are the most sensitive strains to sperm DNA fragmentation, (6) supplementation of CPA solution with either of glycerol or fructose shows a significant protective effect for DNA integrity during cryopreservation in C57BL/6 and 129S mice, (7) supplementation of fructose or glycerol to raffinose significantly improves in vitro fertilization rate in C3B6F1 and C57BL/6 mice, and (8) the rate of sperm DNA fragmentation significantly decreases in vitro embryo development rate to blastocyst in C57BL/6 mice.

\section{Acknowledgements}

This research was supported by Genome Canada through the Ontario Genomics Institute and Genome Prairie; Canadian Institutes of Health Research grants to C M; Canada Foundation for Innovation and Ontario Innovation Trust grants to $\mathrm{C} \mathrm{M}$; and Charles River Canada. C M is a recipient of the Ontario Ministry of Innovation's Early Researcher Award. The authors declare that there is no conflict of interest that would prejudice the impartiality of this scientific work.

\section{References}

Agca Y, Gilmore J, Byers M, Woods EJ, Liu J \& Critser JK 2002 Osmotic characteristics of mouse spermatozoa in the presence of extenders and sugars. Biology of Reproduction 67 1493-1501.

An TZ, Iwakiri M, Edashige K, Sakurai T \& Kasai M 2000 Factors affecting the survival of frozen-thawed mouse spermatozoa. Cryobiology 40 237-249.

Anchordoguy TJ, Rudolph AS, Carpenter JF \& Crowe JH 1987 Modes of interaction of cryoprotectants with membrane phospholipids during freezing. Cryobiology 24 324-331.

Boggs JM \& Rangaraj G 1985 Phase transitions and fatty acid spin label behavior in interdigitated lipid phases induced by glycerol and polymyxin. Biochimica et Biophysica Acta 27816 221-233.

Chohan KR, Griffin JT \& Carrell DT 2004 Evaluation of chromatin integrity in human sperm using acridine orange staining with different fixatives and after cryopreservation. Andrologia 36 321-326.

Critser JK \& Mobraten LE 2000 Cryopreservation of Murine Spermatozoa. ILAR Journal 414.

Critser JK, Huse-Benda AR, Aaker DV, Arneson BW \& Ball GD 1988 Cryopreservation of human spermatozoa. III. The effect of cryoprotectants on motility. Fertility and Sterility $\mathbf{5 0} 314-320$.

Curry MR 1995 Cryopreservation of semen from domestic livestock. Methods in Molecular Biology 38 189-197.

Dandekar PV \& Glass RH 1978 Development of mouse embryos in vitro is affected by strain and culture medium. Gamete Research 17 279-285.

De Leeuw FE, De Leeuw AM, Den Daas JHG, Colenbrander B \& Verkleij AJ 1993 Effects of various cryoprotectiand agents and membrane-stabilizing compounds on bull sperm membrane integrity after cooling and freezing. Cryobiology 30 32-44.

Donnelly ET, McClure N \& Lewis SE 2001 Cryopreservation of human semen and prepared sperm: effects on motility parameters and DNA integrity. Fertility and Sterility $\mathbf{7 6} 892-900$.
Edwards RG \& Beard HK 1999 Is the success of human IVF more a matter of genetics and evolution than growing blastocysts? Human Reproduction 14 1-4.

Flaherty SP, Payne D, Swann NJ \& Mattews CD 1995 Aetiology of failed and abnormal fertilization after intracytoplasmic sperm injection. Human Reproduction 10 2623-2629.

Fraser L \& Strzezek J 2004 The use of comet assay to assess DNA integrity of boar spermatozoa following liquid preservation at 5 and $16{ }^{\circ} \mathrm{C}$. Folia Histochemica et Cytobiologica 42 49-55.

Garcia MA \& Graham EF 1989 Development of a buffer system for dialysis of bovine spermatozoa before freezing. II. Effects of sugars alcohols on post thaw motility. Theriogenology 31 1029-1037.

Hammadeh ME, Greiner S, Rosenbaum P \& Schmidt W 2001 Comparison between human sperm preservation medium and TEST-yolk buffer on protecting chromatin and morphology integrity of human spermatozoa in fertile and subfertile men after freezethawing procedure. Journal of Andrology 22 1012-1018.

Hammerstedt RH, Graham JK \& Nolan JP 1990 Cryopreservation of mammalian sperm: what we ask them to survive. Journal of Andrology 11 73-88.

Ho Y, Wigglesworth K, Eppig JJ \& Schultz RM 1995 Preimplantation development of mouse embryos in KSOM: augmentation by amino acids and analysis of gene expression. Molecular Reproduction and Development 41 232-238.

Honadel TE \& Killian GJ 1988 Cryopreservation of murine embryos with trehalose and glycerol. Cryobiology 25 331-337.

Hoppe PC 1980 Genetic influences on mouse sperm capacitation in vivo and in vitro. Gamete Research 3 343-349.

Hughes CM, Lewis SE, McKelvey-Martin VJ \& Thompson WA 1996 Comparison of baseline and induced DNA damage in human spermatozoa from fertile and infertile men, using a modified comet assay. Molecular Human Reproduction 2 613-619.

Jiang MX, Zhu Y, Zhu ZY, Sun QY \& Chen DY 2005 Effects of cooling, cryopreservation and heating on sperm proteins, nuclear DNA, and fertilization capability in mouse. Molecular Reproduction and Development 72 129-134.

Kasai K, Minato Y \& Toyoda Y 1978 Fertilization and development in vitro of mouse eggs from inbred strains and F1 hybrids. Japanese Journal of Animal Reproduction 28 19-22.

Koshimoto C \& Mazur P 2002 The effect of the osmolality of sugarcontaining media, the type of sugar, and the mass and molar concentration of sugar on the survival of frozen-thawed mouse sperm. Cryobiology 45 80-90.

Larson KL, Dejonge CJ, Barnes AM, Jost LK \& Evenson DP 2000 Sperm chromatin structure assay parameters as predictors of failed pregnancy following assisted reproductive techniques. Human Reproduction 15 1717-1722.

Linfor JJ \& Mayers SA 2002 Detection of DNA damage in response to cooling injury in equine spermatozoa using single-cell gel electrophoresis. Journal of Andrology 23 107-113.

Mazur P 1970 Cryobiology: the freezing of biological systems. Science 22168 939-949.

McGonagle LS, Goldstein M, Feldschuh J \& Foote RH 2002 The influence of cryoprotective media and processing procedures on motility and migration of frozen-thawed human sperm. Asian Journal of Andrology 4 137-141.

Molinia FC, Evans G \& Maxwell WMC 1994 In vitro evaluation of zwitterion buffers in diluents for freezing ram spermatozoa. Reproduction, Nutrition, Development 34 491-500.

Nagy A, Gersenstein M, Vintersten K, Gertsenstein M \& Behringer R 2002 Manipulating the mouse embryo: a laboratory manual. In Recovery, culture, and transfer of embryos and germ cells. 3rd edn, pp 129-188. Cold Spring Harbor Laboratory Press: USA.

Nakagata N 1993 Production of normal young following transfer of mouse embryos obtained by in vitro fertilization between cryopreserved gametes. Journal of Reproduction and Fertility 99 77-80.

Nakagata N 1995 Studies on cryopreservation of embryos and gametes in mice. Experimental Animals 44 1-8. 
Nakagata N 2000 Cryopreservation of mouse spermatozoa. Mammalian Genome 11 572-576.

Nakagata N, Matsumoto K, Anzai M, Takahashi A, Takahashi Y, Matsuzaki Y \& Miyata K 1992 Cryopreservation of spermatozoa of a transgenic mouse. Jikken Dobutsu 41 537-540.

Nishizono H, Shioda M, Takeo T, Irie T \& Nakagata N 2004 Decrease of fertilizing ability of mouse spermatozoa after freezing and thawing is related to cellular injury. Biology of Reproduction 71 973-978.

Niwa K, Araki M \& Iritani A 1980 Fertilization in vitro of eggs and first cleavage of embryos in different strains of mice. Biology of Reproduction 22 1155-1159.

Parks JE \& Graham JK 1992 Effects of cryopreservation procedures on sperm membranes. Theriogenology 38 209-222.

Peris SI, Morrier A, Dufour M \& Bailey JL 2004 Cryopreservation of ram semen facilitates sperm DNA damage: relationship between sperm andrological parameters and the sperm chromatin structure assay. Journal of Andrology 25 224-233.

Polge C, Smith AU \& Parkes AS 1949 Revival of spermatozoa after vitrification and dehydration at low temperatures. Nature 164 666-668.

Quinn P, Kerin JF \& Warnes GM 1985 Improved pregnancy rate in human in vitro fertilization with the use of a medium based on the composition of human tubal fluid. Fertility and Sterility $\mathbf{4 4}$ 493-498.

Ron-el R, Nachum H, Herman A, Golan A, Caspi E \& Soffer Y 1991 Delayed fertilization and poor embryonic development associated with impaired semen quality. Fertility and Sterility 55 338-344.

Roudebush WE \& Duralia DR 1996 Superovulation, fertilization, and in vitro embryo development in BALB/cByJ, BALB/CJ, B6D2F1/J, and CFW mouse strains. Laboratory Animal Science 46 239-240.

Royere D, Hamamah S, Nicolle JC, Barthelemy C \& Lansac J 1988 Freezing and thawing alter chromatin stability of ejaculated human spermatozoa: fluorescence acridine orange staining and FeulgenDNA cytophotometric studies. Gamete Research 21 51-57.

Royere D, Hamamah S, Nicolle JC \& Lansac J 1991 Chromatin alterations induced by freeze-thawing influence the fertilizing ability of human sperm. International Journal of Andrology 14 328-332.

Schneider U \& Mazur P 1984 Osmotic consequences of cryoprotectant permeability and its relation to the survival of frozen-thawed embryos. Theriogenology 21 68-79.

Schwartz NB 1997 Carbohydrate metabolism II: special pathways. In Textbook of Biochemistry, 4 edn, p 307. Ed. TM Devlin. John Wiley and Son: New York, USA.

Scott L \& Whittingham DG 1996 Influence of genetic background and media components on the development of mouse embryos in vitro. Molecular Reproduction and Development 43 336-346.

Seli E, Gardner DK, Schoolcraft WB, Moffatt O \& Sakkas D 2004 Extent of nuclear DNA damage in ejaculated spermatozoa impacts on blastocyst development after in vitro fertilization. Fertility and Sterility 82 378-383.

Songsasen N \& Leibo SP 1997 a Cryopreservation of mouse spermatozoa II. Relationship between survival after cryopreservation and osmotic tolerance of spermatozoa from three strains of mice. Cryobiology 35 255-269.

Songsasen N \& Leibo SP 1997 b Cryopreservation of mouse spermatozoa I. Effect of seeding on fertilizing ability of cryopreserved spermatozoa. Cryobiology 35 240-254.

Storey BT, Noiles EE \& Thampson KA 1998 Comparison of glycerol, other polyols, trehalose, and raffinose to provide a defined cryoprotectant medium for mouse sperm cryopreservation. Cryobiology 37 46-58.

Strauss G, Schurtenberger P \& Hauser H 1986 The interaction of saccharides with lipid bilayer vesicles: stabilization during freezethawing and freeze-drying. Biochimica et Biophysica Acta 858 69-180.

Sztein JM, Farley JS \& Mobraaten LE 2000 In vitro fertilization with cryopreserved inbred mouse sperm. Biology of Reproduction $\mathbf{6 3}$ 1774-1780.

Sztein JM, Noble K, Farley JS \& Mobraaten LE 2001 Comparison of permeating and nonpermeating cryoprotectants for mouse sperm cryopreservation. Cryobiology 42 28-39.

Tada N, Sato M, Yamanoi J, Mizorogi T, Kasai K \& Ogawa S 1990 Cryopreservation of mouse spermatozoa in the presence of raffinose and glycerol. Journal of Reproduction and Fertility 89 511-516.

Takeshima T, Nakagata N \& Ogawa S 1991 Cryopreservation of mouse spermatozoa. Jikken Dobutsu 40 493-497.

Tesarik J, Greco E \& Mendoza C 2004 Late, but not early, paternal effect on human embryo development is related to sperm DNA fragmentation. Human Reproduction 19 611-615.

Thampson KA, Richa J, Liebhaber SA \& Storey BT 2001 Dialysis addition of trehalose/glycerol cryoprotectant allows recovery of cryopreserved mouse spermatozoa with satisfactory fertilizing ability as assessed by yield of live young. Journal of Andrology 22 339-344.

Thornton CE, Brown SD \& Glenister PH 1999 Large numbers of mice established by in vitro fertilization with cryopreserved spermatozoa: implications and applications for genetic resource banks, mutagenesis screens, and mouse backcrosses. Mammalian Genome $\mathbf{1 0}$ 987-992.

Traina ME, Rescia M, Urbani E, Mantovani A, Macri C, Ricciardi C, Stazi AV, Fazzi P, Cordelli E, Eleuteri P et al. 2003 Long-lasting effects of lindane on mouse spermatogenesis induced by in utero exposure. Reproductive Toxicology 17 25-35.

Watson PF 1979 The preservation of semen in mammals, Oxford Reviews of Reproduction Biology, Oxford: Oxford Universtiy Press, pp 283-351.

WHO Health Organization 1999 Organization Laboratory Manual for the Examination of Human Semen and Sperm-cervical Mucus Interaction, 4 Cambridge: Cambridge University Press.

Willoughby CE, Mazur P, Peter AT \& Critser JK 1996 Osmotic tolerance limits and properties of murine spermatozoa. Biology of Reproduction 55 715-727.

Yildiz C, Kaya A, Aksoy M \& Tekeli T 2000 Influence of sugar suplementation of the extender on motility, viability, and acrosomal integrity of dog spermatozoa during freezing. Theriogenology $\mathbf{5 4}$ 579-585.

Yokoyama M, Akiba H, Katsuki M \& Nomura T 1990 Production of normal young following transfer of mouse embryos obtained by in vitro fertilization using cryopreserved spermatozoa. Jikken Dobutsu 39 125-128.

Received 6 October 2006

First decision 10 November 2006

Accepted 8 December 2006 